\title{
Myocardial disarray in Noonan syndrome
}

Michael Burch, Jessica M Mann, Michael Sharland, Elliot A Shinebourne, Michael A Patton, William J McKenna

Departments of genetic defect remains to be determined.

Clinical Genetics anc

Cardiological

Sciences, St George's

Hospital Medical

School, London

J M Mann

$M$ Sharland

M A Patton

W J McKenna

Brompton Hospital,

London

M Burch

E A Shinebourne

Correspondence to:

Dr William J McKenna,

Department of Cardiologica

Sciences, St George's

Hospital Medical School,

Cranmer Terrace, London

SW 17 ORE.

Accepted for publication

3 August 1992 (Br Heart J 1992;68:586-8)

Asymmetrical septal hypertrophy has been documented in $23 \%$ of patients with Noonan

Table 1 Patient details

\begin{abstract}
Objective-To characterise the histopathology of the left ventricular hypertrophy commonly associated with Noonan syndrome by assessing the extent of myocyte disarray and therefore to define one aspect of the relation between this disease and idiopathic hypertrophic cardiomyopathy.
\end{abstract}

Design-Blinded histological analysis.

Setting-Hospital medical school.

Patients-Six hearts of children with the Noonan phenotype and isolated ventricular hypertrophy were compared with age and sex matched controls.

Methods-Histological analysis was performed with an image analyser under light microscopy. Representative sections from the entire left ventricular free wall were examined. Results were expressed as the percentage of fields showing disarray related to the number of fields evaluated: 100 fields were examined for each patient.

Results-In the patients with Noonan syndrome myocardial disarray was present in the ventricular septum in 24 $(5 \cdot 7) \%$ (mean (SD)) of fields and in the free wall in $22 \cdot 2(6 \cdot 8) \%$. In the controls disarray was present in the septum in 3.8 $(2 \cdot 3) \%$ of fields and in the free wall in 2.4 $(2 \cdot 8) \%$. In both regions the extent of disarray was significantly greater in patients with Noonan syndrome $(p<0.0005 ; 95 \%$ confidence interval 14 to $26 \cdot 3$ for the septum: $p<0.005,95 \%$ confidence interval 11.4 to $28 \cdot 2$ for the free wall).

Conclusions-The ventricular hypertrophy associated with Noonan syndrome is histologically similar to hypertrophic cardiomyopathy but whether the two diseases are the expression of the same

\begin{tabular}{llllll}
\hline $\begin{array}{l}\text { Patient } \\
\text { Number }\end{array}$ & Sex & Symptoms & $\begin{array}{l}\text { Death }(D) \\
\text { or transplant }(T)\end{array}$ & $\begin{array}{l}\text { Age at }(D) \\
\text { or }(T) \text { (month) }\end{array}$ & Echo \\
\hline 1 & M & SOBE & T & 120 & Symm BVH \\
2 & F & CCF & D & 2 & ASH \\
3 & F & CCF & D & 6 & ASH \\
4 & SOBE & CCF & D & 24 & ASH \\
5 & M & CCF & D & 4 & ASH \\
6 & M & CCF & D & $0 \cdot 25$ & \\
\hline
\end{tabular}

ASH, asymmetrical ventricular hypertrophy; $\mathrm{CCF}$, congestive cardiac failure; Echo, cross sectional echocardiography; SOBE, shortness of breath on exertion; Symm BVH, symmetrical biventricular hypertrophy. syndrome. ${ }^{1}$ The clinical and prognostic significance of this finding, however, is uncertain. In particular the relation to classic hypertrophic cardiomyopathy has not been assessed. Histopathological similarity between the two conditions could have both genetic and clinical implications. To characterise the histopathology we examined the hearts from six patients with Noonan syndrome and left ventricular hypertrophy who died in low cardiac output (4) or were given transplants (2) and compared the results with those in age matched controls.

\section{Patients and methods}

Table 1 shows the patients' details. Echocardiography was performed in four sets of parents of the six patients with Noonan syndrome and was normal in all eight, though one of them showed the Noonan phenotype. The age and sex matched controls were selected from among children dying of non-cardiac causes.

\section{METHODS}

In all cases a transverse section of the ventricles was obtained, about one half the distance between the aortic valve and the left ventricular apex. Tissue specimens were fixed in formalin, embedded in paraffin, sectioned at a thickness of $6 \mu \mathrm{m}$ and stained with haematoxylin and eosin. This permitted assessment of the ventricular septum and the left ventricular free wall in the same plane.

Myocardial disarray was evaluated with an image analyser (Optomax V, Analytical Measuring Systems, Cambridge, UK), under light microscopy at a magnification of $\times 16$. The screen of the image analyser was regarded as a field, and the presence or absence of disarray was determined within that field. We classified cardiac muscle cell disorganisation according to the four different types that have been described in detail elsewhere. ${ }^{2-4}$ In type IA the muscle cells were aligned perpendicularly or obliquely ("pinwheel"). Type IB consisted of relatively broad bundles of muscle that were orientated in an oblique or perpen- 

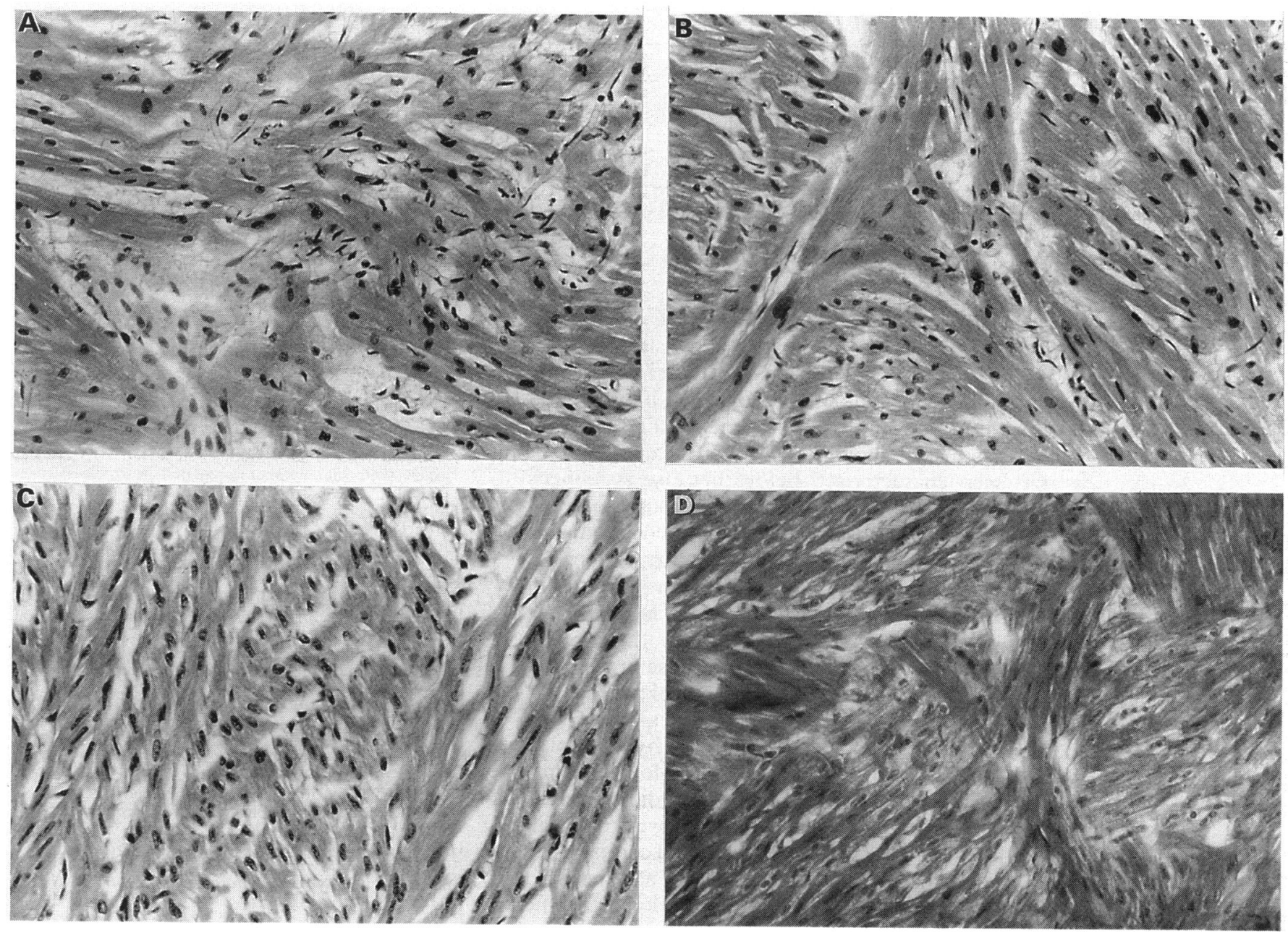

Types of disarray shown in Noonan syndrome. (A) type IA; (B) type IB; (C) type IIA; (D) type IIB.

dicular way. Type IIA disorganisation consisted of narrow longitudinal bundles between transversely cut cells. Type IIB was similar to IIA but the bundles of longitudinal muscles were more linear. Therefore type I disorganisation involved areas in which cardiac muscle cells were cut longitudinally and type II disorganisation involved both longitudinally and transversely cut cardiac muscle cells.

The ventricular septum was evaluated in all patients with Noonan syndrome, and 100 fields per section were counted for each patient. It was possible to evaluate the left ventricular free wall in only five of the six patients with Noonan syndrome (sections were not available in one patient). Both the ventricular septum and the free wall were evaluated in all six age matched controls: again 100 fields per section were analysed.

The extent of disarray was expressed as the percentage of total fields in which disarray was

Table 2 Disarray in ventricular septum (total number of fields showing disarray in a 100 fields examined for each patient

\begin{tabular}{lllrrl}
\hline Patient & $I A$ & $I I A$ & $I B$ & $I I B$ & Total \\
\hline 1 & $1(1)$ & $0(0)$ & $10(2)$ & $11(0)$ & $22(3)$ \\
2 & $1(0)$ & $2(0)$ & $9(0)$ & $4(0)$ & $16(0)$ \\
3 & $1(1)$ & $8(0)$ & $3(4)$ & $18(0)$ & $30(5)$ \\
4 & $1(1)$ & $3(1)$ & $12(2)$ & $15(3)$ & $31(7)$ \\
5 & $1(1)$ & $7(0)$ & $2(0)$ & $14(3)$ & $24(4)$ \\
6 & $1(0)$ & $3(2)$ & $2(0)$ & $15(2)$ & $21(4)$ \\
\hline
\end{tabular}

Data from age matched controls are given in parentheses. present. All patterns of myocyte disarray were included in the assessment. The severity of disarray in each field was not assessed-merely its presence or absence.

Non parallel arrangements of cardiac muscle cells were not considered to represent disorganisation if they were in areas where cells normally converge at acute angles-ie, $(a)$ the junction of the ventricular septum with the left and right ventricular free walls, $(b)$ within trabeculations, $(c)$ within scarred areas, and $(d)$ at points of convergence of major muscle bundles or adjacent to interstitial spaces containing blood vessels. ${ }^{34}$ Intraobserver variation was $<2 \%$.

Data were expressed as the percentage of fields and means (SD) were compared by Student's non-paired $t$ test.

\section{Results}

The figure shows the histological appearances of myocardial disarray in Noonan syndrome. Tables 2 and 3 show the total number of fields in which myocardial disarray was present in each patient. The percentage of disarray was significantly greater in patients with Noonan syndrome than in controls for both the ventricular septum $(24.0(5 \cdot 7)$ v $3.8(2.3), \mathrm{p}<$ $0.0005,95 \%$ confidence interval 14 to $26 \cdot 3)$ and the free wall $(22 \cdot 2(6.8) v 2.4(2 \cdot 8), \mathrm{p}<0.005$, $95 \%$ confidence interval $11 \cdot 4$ to $28 \cdot 2$ ). 
Table 3 Disarray in left ventricular free wall

\begin{tabular}{llllll}
\hline Patient & $I A$ & $I I A$ & $I B$ & $I I B$ & Total \\
\hline 1 & $6(0)$ & $7(1)$ & $1(0)$ & $6(0)$ & $20(1)$ \\
2 & $1(0)$ & $7(0)$ & $1(0)$ & $10(7)$ & $19(7)$ \\
3 & $1(0)$ & $1(1)$ & $1(0)$ & $14(0)$ & $17(1)$ \\
4 & $1(0)$ & $10(1)$ & $9(1)$ & $14(1)$ & $34(3)$ \\
6 & $0(0)$ & $7(0)$ & $0(0)$ & $14(0)$ & $21(0)$ \\
\hline
\end{tabular}

Data from age matched controls are given in parentheses.

\section{Discussion}

The characteristic phenotype of a group of patients with pulmonary stenosis was first described by Noonan. ${ }^{56}$ Later it became apparent that left ventricular hypertrophy could occur in these patients. ${ }^{7-9}$ The myocardial histopathology of this hypertrophy has not been characterised before because specimens are rare. We have collected a unique series of hearts and using a quantitative morphometric technique have shown that the extent of myocardial disarray was significantly greater in hearts from patients with Noonan syndrome and left ventricular hypertrophy than in age and sex matched controls. Because myocardial disarray affecting more than $5 \%$ of the sections obtained from the ventricular septum is a sensitive and specific marker for hypertrophic cardiomyopathy,${ }^{2-4}$ a histopathological similarity between hypertrophic cardiomyopathy and the hypertrophy of Noonan syndrome can be inferred. It was not possible to compare the extent of disarray directly as no age matched specimens from children with hypertrophic cardiomyopathy without Noonan syndrome were available. Death in hypertrophic cardiomyopathy is usually sudden and occurs in older children and adolescents, while death in Noonan syndrome is more often earlier and from cardiac failure. ${ }^{81011}$

Hypertrophic cardiomyopathy is known to be inherited as an autosomal dominant disease in over $50 \%$ of cases, ${ }^{12}$ but none of the parents (including one with the Noonan phenotype) who were screened echocardiographically showed hypertrophy. Noonan syndrome, although often sporadic, can be familial and is also inherited as an autosomal dominant trait. ${ }^{13}$ Angiographic $^{3}$ and echocardiographic ${ }^{14}$ evidence of transmission of left ventricular abnormalities from parent to child has been reported. Thus it can be argued that despite clinical differences hypertrophic cardiomyopathy and the ventricular hypertrophy associated with Noonan syndrome share a common genetic defect. Whether the two conditions are truly the same or whether hypertrophic cardiomyopathy is a heterogeneous group of diseases, as had been speculated ${ }^{15}$ can only be established when the molecular genetic defects are identified. ${ }^{16}$

1 Nora JJ, Lortsher RH, Spangler R. Echocardiographic studies of left ventricular disease in Ullrich-Noonan Syndrome. Am J Dis Child 1975;129:1417-20.

2 Maron BJ, Sato N, Roberts WC, Edwards JE, Chandra RS. Quantitative analysis of cardiac muscle cell disorganisation in the ventricular septum. Comparison of fetuses and infants with and without congenital heart disease and infants with and without congenital heart disease and
patients with cardiomyopathy. Circulation 1979;60: patients

3 Maron BJ, Roberts WC. Quantitative analysis of cardiac muscle cell disorganisation in the ventricular septum of patients with hypertrophic cardiomyopathy. Circulation

4 Maron BJ, Anan TJ, Roberts WC. Quantitative analysis of the distribution of cardiac muscle cell disorganisation of the left ventricular wall of patients with hypertrophic cardiomyopathy. Circulation 1981;63:882-94.

5 Noonan JA, Ehmke DA. Associated non-cardiac malformations in children with congenital heart disease. Am J Dis Child 1963;63:468-70.

6 Noonan JA. Hypertelorism with Turner phenotype. A new syndrome with associated congenital heart disease. Am J Dis Child 1968;116:373-80.

7 Ehlers KH, Engle MA, Levin AR, Deely W. Eccentric ventricular hypertrophy in familial and sporadic instances of $46 \mathrm{xx}, \mathrm{xy}$ Turner phenotype. Circulation 1972;45: $639-52$.

8 Hirsch HD, Gelband H, Garcia O, Gottlieb S, Tamer DM. Rapidly progressive obstructive cardiomyopathy in Rapidly progressive obstructive cardiomyopathy in
infants with Noonan Syndrome. Circulation 1975;52: infants

9 Phornphutkul C, Rosenthal A, Nadas AS. Cardiomyopathy in Noonan syndrome. Br Heart J 1973;35:99-102.

10 Maron BJ, Henry WL, Clark CE, Redwood DR, Roberts WC, Epstein JE. Asymmetric septal hypertrophy in childhood. Circulation 1976;53:9-14.

11 McKenna WJ, Deanfield JE. Hypertrophic cardiomyopathy: an important cause of sudden death. Arch Dis Child 1984;59:971-5.

12 Greaves SC, Roche AHG, Neutze JM, Whitlock RML, Veale AMO. Inheritance of hypertrophic cardiomyopathy: a cross sectional and M-Mode echocardiographic study of 50 families. Br Heart J 1987;58:259-66.

13 Nora JJ, Sinha AK. Direct familial transmission of the Turner phenotype. Am J Dis Child 1968;116:343-6.

14 Scaravilli EP, Pontillo D, Pennacchia F, Boccanelli A, Greco C, Lo Schiavo P. La cardiomiopatia ipertrofica associata alla sindrome di Noonan e la stenosi soltovalvolare aortica membranosa associata alla sindrome di Turner. G Ital Cardiol 1987;17:800-6.

15 Davies MJ. Hypertrophic cardiomyopathy: one disease or several? Br Heart J 1990;63:263-4.

16 Jarcho JA, McKenna W, Pare P, et al. Mapping a gene for familial hypertrophic cardiomyopathy to chromosome 14ql. N Engl J Med 1989;321:1372-8. 